\title{
Laboratory Investigation of Slamming Load Contribution of Plunging Breaker
}

\author{
De Wang Chia ${ }^{1,2}$, Xin Wang ${ }^{2}$, Arun $\mathrm{Kr} \mathrm{Dev}^{2}$, Longbin Tao ${ }^{3}$ and Yali Zhang,* \\ ${ }^{1}$ Lloyd's Register Singapore Pte Ltd, Singapore 138522, Singapore \\ ${ }^{2}$ Faculty of Science, Agriculture and Engineering, Newcastle University, \\ Newcastle Upon Tyne, NE1 7RU, United Kingdom \\ ${ }^{3}$ Naval Architecture, Ocean and Marine Engineering, University of Strathclyde, \\ Glasgow G4 0LZ, United Kingdom \\ xin.wang@ncl.ac.uk
}

\begin{abstract}
Plunging breakers could induce one of the most devastating forces on an offshore structure. As compared to non-breaking wave, a plunging breaker would induce an additional slamming load on an offshore structure. Current industry guidelines for design breaking wave slamming coefficient do not take into account of the geometric cross section of the offshore structures and the breaking wave parameters. The slamming load is affected by a few factors; the capability of the structure to entrap air upon the onset of plunging breakers, breaking wave parameter - rise time, just to name a few. This research paper attempts to expand the correlation of the slamming load coefficient to the geometric cross section of the section and the rise time of the impact breaking wave. It was found out that the geometrical cross section of cylinders do have significant impact on the slamming coefficient. The rise time of the plunging breaker does have an impact on the slamming load itself, but the impact the rise time had on the slamming coefficient is indistinctive.
\end{abstract}

Keywords: Plunging wave, Slamming Load, Breaking wave.

\section{Nomenclature}

$C_{b} \quad$ phase celerity of breaking wave

$C_{D} \quad$ drag coefficient

$C_{M} \quad$ inertia coefficient

$C_{S} \quad$ slamming coefficient

$C_{w} \quad$ waterplane area coefficient

d water depth

$D \quad$ cylinder diameter

$f_{P} \quad$ peak wave frequency

$F_{D} \quad$ drag force

$F_{I} \quad$ inertia force

$F_{S} \quad$ slamming force

* Currently affiliated with Technology Centre for Offshore and Marine, Singapore 118411, Singapore 


$\begin{array}{ll}F & \text { total force } \\ g & \text { gravitational acceleration } \\ H_{b} & \text { height of breaking wave } \\ k & \text { wave number } \\ \lambda & \text { wavelength } \\ \lambda_{C} & \text { curling factor } \\ \zeta & \text { surface elevation } \\ \zeta_{b} & \text { maximum surface elevation } \\ \rho_{w} & \text { water density } \\ \phi_{n} & \text { phase shift } \\ P & \text { slamming pressure } \\ S_{J} & \text { JONSWAP spectrum } \\ T & \text { wave period } \\ t_{B} & \text { time of breaking } \\ t_{i} & \text { rise time } \\ u & \text { horizontal wave particle velocity } \\ \omega & \text { wave angular frequency } \\ \omega_{P} & \text { peak wave angular frequency } \\ X_{\mathrm{B}} & \text { spatial location of breaking } \\ \gamma^{r} & \text { peak enhancement factor }\end{array}$

\section{Introduction \& Literature Review}

Offshore structures and ships are exposed to environmental loads at sea. Of which, breaking wave impact force are likely to dominate. Under normal circumstances, while considering hydrodynamic force acting on a slender cylinder $\left(\frac{D}{\lambda}\right)>0.2$, the Morison's Equation (Eq. 1, Eq.2 \& Eq.3) is being used to consider such wave forces.

$$
\begin{gathered}
F=F_{I}+F_{D} \\
F_{I}=\int_{-d}^{\zeta_{b}} C_{M} * \rho_{w} * \frac{\pi * D^{2}}{4} * \frac{\partial u(z)}{\partial t} * d z
\end{gathered}
$$

Where $A_{\mathrm{R}}=$ Reference impact area of the structure perpendicular to the wave propagation, $A_{\mathrm{R}}=H_{\mathrm{b}} * D ; H_{\mathrm{b}}$ represents the reference height from the wave breaking elevation $\left(\zeta_{b}\right)$ to the cylindrical bottom $(-d)$ as shown in (Eq. 3)

$$
F_{D}=\int_{-d}^{\zeta_{b}} 0.5 * \rho_{w} * C_{D} * D * u(z) *|u(z)| * d z
$$

However, while considering hydrodynamic forces that are of highly non-linearity in nature, like the breaking waves force, the Morison's Equations, together with commonly used potential theory, will be rendered invalid in such situations. As the plunging breaker would induces a sharp increment of load onto the structure over a very short period of time. Goda [2] introduced the slamming load component to the 
Morison's Equation to account for the breaking wave impact loading; the addition of slamming load induced by the collapsing plunging breaker's jet (Eq. 4 \& Eq. 5)

$$
\begin{gathered}
F=F_{I}+F_{D}+F_{S} \\
F_{S}=0.5 * \rho_{w} * C_{S} * D * C_{b}^{2} * \lambda_{C} * \zeta_{b}
\end{gathered}
$$

Curling factor $\left(\lambda_{C}\right)$; a ratio of breaking wave impact height on structure over the breaking wave height.

Eq. 5 states that the design slamming load contribution is dependent on the slamming load coefficient and the breaking wave celerity.

\subsection{Slamming Load Coefficient $\left(\mathrm{C}_{\mathrm{S}}\right)$}

According to classification society design rulebook [3], there are guidelines on estimating the inertia, drag and slamming coefficient of the offshore structure. The inertia and drag coefficient were affected by a few parameters; surface roughness, Keuleugan Carpenter Number and structure geometrical shape. However the maximum slamming load coefficient had a fixed value for all scenarios, $C_{S}=5.15$ at the point of initial jet contact with the offshore structure. This might give rise to the possibility of an overly conservative design criterion.

Campbell and Weynberg [4] did experimental works on the slamming force on a cylinder. A velocity transducer was attached on the test cylinder to record the input velocity and a force transducer output will be used to calculate the resultant slamming coefficient (Eq. 5). Campbell and Weynerg [4] found out that the highest slamming coefficient was found to occur upon the initial contact, at $C_{S}=5.15$, and this value was also later used by the classification society [3]. SPM [5] states that for design purpose, the slamming contribution could be approximated as $250 \%$ of the design drag force.

De Wang and Xin Wang [6] generate plunging breaker to impact on cylinders with different geometrical cross sections; square shape cylinder, circular cylinder and diamond shape cylinder. De Wang and Xin Wang [6] found out that the design slamming coefficient would only seemed appropriate for a flat plate square cylinder; obtaining a value of about 3.9. Whereas the diamond shaped cylinder and circular cylinder, reported a slamming coefficient of less than 3. De Wang and Xin Wang [6] concluded using different cylindrical geometrical cross-section would give different wave contact angle and different waterplane area. This would give rise to different interfacial aeration during the onset of plunging breaker, between the collapsing jet and the structure, and different air entrapment properties which would have a direct impact on the slamming load coefficient.

\subsection{Breaking Wave Kinematics $\left(C_{B}, u\right)$}

In approaching shallow water, the shallow water wave celerity, $c=(g * d)^{0.5}$ is applied. The value of the wave celerity will decrease together with the decreasing depth. Hence at a point, the horizontal wave particle velocity will finally surpass the decreas- 
ing wave phase celerity, and forming a protruding jet and allowing the jet to collapsing.

In deep water, the phase celerity does not reduce due to shoaling effects. However, plunging breakers still occur due to the horizontal wave particle velocity reaching a critical level. In Rapp and Melville [7] experimental work, they found that right before the onset of plunging breakers, the phase celerity observed a reduction.

$$
c=\frac{g * T}{2 \pi}
$$

Perlin [8] created breaking waves via dispersive focusing, which involved using a range of wave frequencies to allow focusing on a pre-determined focal point, to allow the wave amplitude to reach critical amplitude, promoting instability, encouraging breaking. Perlin found that the wave length recorded by the PIV (Particle Image Velocimetry) before breaking is $0.7 \mathrm{~m}$, which gives linear theory derived phase celerity of $1.05 \mathrm{~ms}^{-1}$ (Eq. 6). However, the wave celerity values measured by the PTV (Particle Tracking Velocimetry), was $1.08 \mathrm{~ms}^{-1}$. This shows a $3 \%$ deviation of the wave celerity as compared to linear theory.

Baldock et al [9] generates plunging breaker and also concluded that the actual value of the phase celerity is $3 \%$ higher than the value calculated using linear theory, which seems to be agreeable with Perlin [8] findings. Cui Cheng [10] did research on the behavior of the kinematics of non-breaking freak waves. He found out that the kinematics of the freak waves tend to deviate even more from the linear theory for waves with a higher steepness value.

De Wang and Longbin [11] expanded Cui Cheng's research and generated plunging breaker of various intensities; varying input spectrum. High speed camera with a recording frequency of $200 \mathrm{~Hz}$ were used for the capture of wave kinematics, together with wave probes at few pre-determined locations to calculate the linear wave celerity. De Wang and Longbin [11] concluded that the phase celerity recorded by the high speed cameras could range from $7 \%$ to $24 \%$ higher than the phase celerity recorded by the linear theory (Eq. 6).

Horizontal crest particle velocity is a heavily researched and important kinematic, as it could relates to few phenomenon; wave breaking kinematic criteria, breaking wave impact loading etc. Perlin [8] also concluded that the horizontal crest particle velocity at the crest starts to accelerate horizontally during the onset of breaking, surpassing the phase celerity. Baldock et al [9] also mentioned that the horizontal crest particle velocity could also be underestimated using the linear theory. Baldock concludes that at wave breaks at higher steepness (higher nonlinearity), the use of linear theory for calculating horizontal crest particle velocity may not be suitable.

Current classification society rules [3] state that, while estimating the kinematics of breaking waves for calculating the design slamming load. The kinematics of the breaking wave is assumed to be ' $120 \%$ of the most probable breaking celerity' to offset the potential unknowns of the kinematics of breaking waves. De Wang \& Longbin [11] also noted higher deviations between the 2 celerity values for the plunging breakers with higher breaking steepness (nonlinearities), agreeing with Cui Cheng 
[10] and Baldock [9] earlier findings that linear theory would not be suitable to calculate wave kinematics of higher nonlinearity.

\subsection{Rise Time $\left(\mathbf{t}_{\mathbf{i}}\right)$}

Blackmore and Hewson [12] investigated the slamming pressure on beach walls at different locations in England. They concluded that a lower rise time $\left(t_{\mathrm{r}}\right)$, would result in the highest slamming pressure, and vice versa. Chan and Melville [1] created plunging breakers using focused wave method. Plunging breakers were created to impact on a vertical wall; and the spatial location of the vertical wall would be shifted further upstream or downstream to investigate on the plunging breaker slamming load contribution at different stages of plunging breaking. Chan and Melville [1] classified breaking wave impact to 3 different regions; the breaking wave impact, the transition zone, and the broken wave impact. The breaking wave impact zone, is defined by an immature form of plunging breaker, with an immature jet forming at the crest. The transition zone is characterized by a more mature jet with higher air entrainment; curl of jet. Finally the broken wave impact is the final form of the plunging jet, with the mature jet starting to collapse downwards onto the vertical wall.

Chan and Melville [1] concluded that the slamming pressure maxima occur when immature jet is form. Although there is lesser air entrainment at this break wave impact zone, however, there is more air entrapment during the impact of the plunging jet. Chan and Melville [1], agreeing with Blackmore and Hewson [12] findings, also associated the critical slamming pressure with lower Rise time.

\section{Experimental Set-up}

Plunging breakers were generated at Newcastle University's Wind, Wave and Current Tank. The tank measures $11 \mathrm{~m}, 1.8 \mathrm{~m}$ and $2 \mathrm{~m}$, length, width and height respectively. A working depth of $1 \mathrm{~m}$ was used for the experiment set up, deep-water condition was assumed for this experimental work; $(d / \lambda)>0.5$.

Taking $x=0 \mathrm{~m}$ at the wave piston. The designated location of the focal point was $x$ $=9 \mathrm{~m}$. However, the resultant breaking point would tend to be nearer to the wave piston, due to non-linearity effects [7]. In this case, also taking into consideration of the spatial location of the immature plunging jet; that would have the most destructive plunging breaker force [1]. The resultant breaking point is at $x_{\mathrm{B}}=8.25 \mathrm{~m}$. Plunging breakers were created using the focusing method [1], using JONSWAP spectrum (Eq. 7).

$$
S_{J}(\omega)=\frac{\alpha * g^{2}}{\omega^{5}} * \exp \left[-1.25 *\left(\frac{\omega_{p}}{\omega}\right)^{4}\right] * \gamma^{r}
$$

The JONSWAP spectrum describes the irregular sea state with dozens of regular waves with varying frequencies, in this experimental work, the frequency range of the JONSWAP spectrum in this experimental work was $0.25 \mathrm{~Hz} \leq f \leq 2 \mathrm{~Hz}$, (note 
$\omega_{P}=2 * \pi * f_{P}$ ). This wave maker is programmed to create a fixed number of regular waves according to the frequency range used for the JONSWAP spectrum (Eq. 8). Taking ' $N$ ' = the number of wave components.

$$
N=1+\left(\left(f_{\max }-f_{\min }\right) * 2^{6}\right)
$$

The individual wave component amplitude could be calculated as (Eq. 9),

$$
\zeta_{n}=\sqrt{2 * S(\omega) * \Delta \omega}
$$

Applying Eq. 7 and Eq. 9, the amplitude and the spectrum could be adjusted by modifying the peak oscillating frequency $\left(\omega_{\mathrm{P}}\right)$. Having a lower $\omega_{\mathrm{P}}$, would relates to having a stronger wave signal (Eq. 7), this in return would yields stronger wave amplitude (Eq. 9). In this experimental work, $0.47 \mathrm{~Hz} \leq f_{\mathrm{P}} \leq 0.5 \mathrm{~Hz}$ were used to create plunging breakers.

$$
\zeta=\zeta_{n} * \cos \left(k_{n} x_{B}-\omega_{n} t_{B}+\phi_{n}\right)
$$

The value of the wave amplitude is bounded by the space $(x)$ and time domain $(t)$ (Eq. $10)$. The spatial location of breaking $\left(x_{B}\right)$ and the time of breaking $\left(t_{B}\right)$ had been predetermined. To generate a breaking wave, the amplitude could be superposition until it reaches critical amplitude, and finally breaks due to instability.

$$
\cos \left(k_{n} x_{B}-\omega_{n} t_{B}+\phi_{n}\right)=1
$$

After determining $x_{B}$ and $t_{B}$, and the individual wave components parameters $k_{n}$ and $\omega_{n}$. The phase shift of each wave component is programmed such a way that it satisfies Eq. 11, to ensure all the wave components would superposition at the predetermined spatial location to allow the resultant wave to reach critical amplitude for breaking (Eq. 10).

\subsection{Equipment Set ups}

2 Go Pro Hero-6 Cameras with a recording frequency of $240 \mathrm{~Hz}$ would be used to record the profile view of the plunging breaker. Sony Camera RX100 with a recording frequency of $1000 \mathrm{~Hz}$ would be used to record the plan view of the plunging breaking impacting on the cylindrical structure. Force transducer with recording capacity of $250 \mathrm{~N}$ per axial ( 3 axial), having a recording frequency of $200 \mathrm{~Hz}$ would be mounted on the top of the hanging cylinder (fixed-free position). 3 wave probes with a recording frequency of $200 \mathrm{~Hz}$ would be placed at $x=7.75 \mathrm{~m}, 8 \mathrm{~m}$, and $8.25 \mathrm{~m}$ respectively. 2 Acoustic Doppler Velocimeter (ADV), having a recording frequency of $200 \mathrm{~Hz}$ and capable of recording 3 axis kinematics would also be used. 


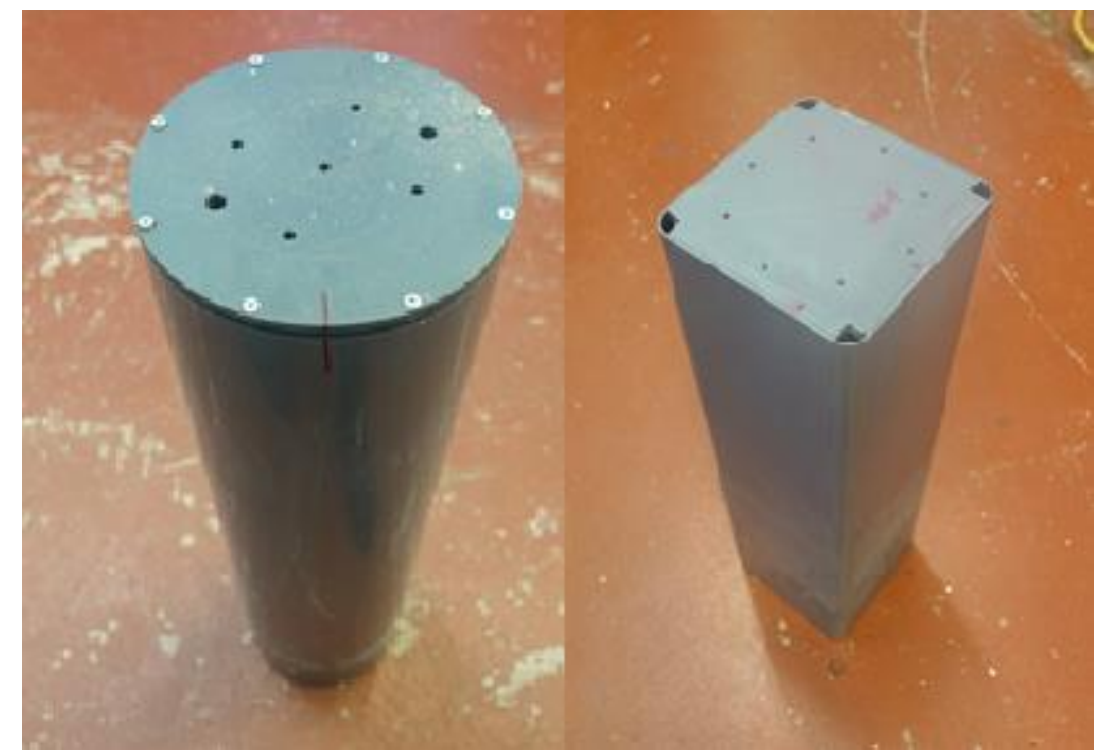

Fig. 1 Circular cylinder and the Square cylinder

A total of 5 cylinders were used, circular cylinder with diameter of $200 \mathrm{~mm}, 315 \mathrm{~mm}$, and $400 \mathrm{~mm}$ respectively, and a square cylinder with a diameter of $200 \mathrm{~mm}$ and a diamond cylinder (diamond cylinder is actually a 45 degree offset about the vertical axis of the square cylinder) (Fig. 1)

\subsection{Post-Processing}

The values of the horizontal particle velocity will be captured by the ADV which will be placed at different elevations, to capture the wave kinematics behavior with function of elevation. Each surface elevation $(\Delta z=30 \mathrm{~mm})$ wave kinematics for both nonbreaking and breaking case would be captured 10 times each.

A regular wave case will be run 10 times per test cylinder. The non-breaking coefficient, namely the drag coefficient and mass coefficient would be estimated from the non-breaking wave case. Recalling inertia force component formula (Eq. 2) and drag force component formula (Eq. 3), the inertia force is a function of ${ }^{\prime} \frac{\partial u(z)}{\partial t}$ ' and the drag force is a function of ' $u(z)$ '. Applying the relationship of ' $\frac{\partial u(z)}{\partial t}$ ' \& ' $u(z)$ ', when $\frac{\partial u(z)}{\partial t},=$ maximum, ' $u(z) '=$ zero, and vice versa. The drag force component of the regular wave case could be extracted (Eq. 3) when ' $\frac{\partial u(z)}{\partial t}$, \& inertia force are negligible. Likewise, the inertia force component could also be approximated when ' $u(\mathrm{z})$ ' and drag force are negligible. With the known contributions of the drag and inertia force, the non-breaking coefficient, drag coefficient and mass coefficient.

Next, for each of the 5 test cylinder cases, 4 breaking wave cases, having $0.47 \mathrm{~Hz} \leq$ $f_{\mathrm{P}} \leq 0.5 \mathrm{~Hz}$ were generated. After estimating the non-breaking coefficients, the drag and inertia force components of the breaking wave case could be approximated to- 
gether with the known kinematics. Subsequently the slamming force contribution and the slamming coefficient could be derived (Eq. 4 \& Eq.5).

The slamming force coefficient was derived, from using cylinders with different geometrical cross-sections.

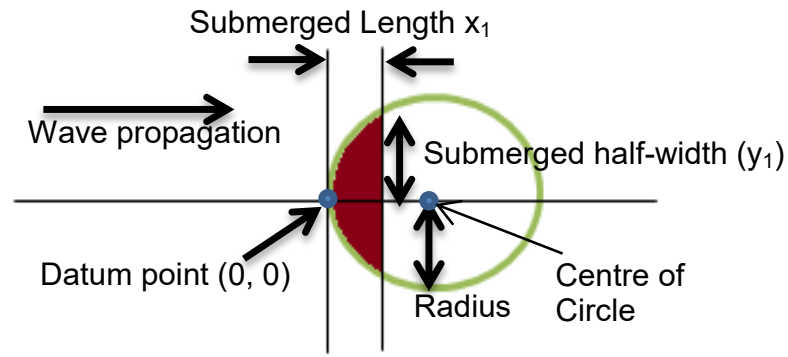

Fig. 2 Coefficient of waterplane of circular cylinder [6]

$$
\begin{gathered}
x_{1}=t_{i} * C_{b} \\
y_{1}^{2}=r^{2}-\left(r-x_{1}\right)^{2} \\
y_{1}=\sqrt{2 * x_{1} * r-x_{1}^{2}}
\end{gathered}
$$

The geometrical cross sections of the cylinders are expected to have a direct influence over the slamming coefficient because it affects the air entrapment between the cylindrical structure and the plunging jet. With the known submerged length and width of the cylindrical structures (Fig. 2, Eq $12-14$ ), the coefficient of waterplane area $\left(C_{\mathrm{W}}\right)$ could be established. 


\section{$3 \quad$ Results \& Discussion}

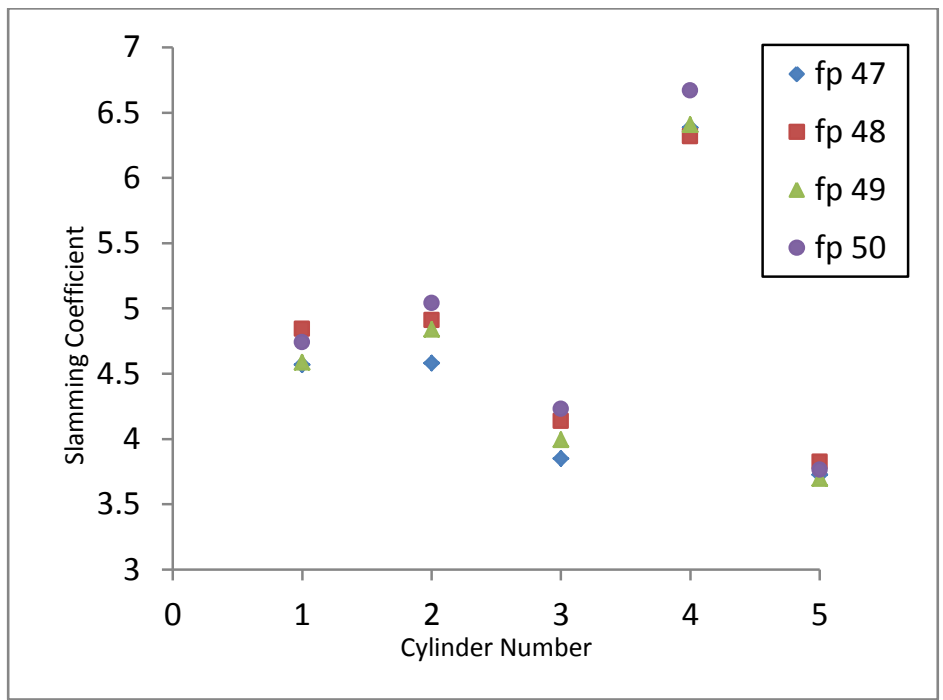

Fig. 3 Maximum slamming coefficient of 5 cylinder test case, with varying breaking intensities (1-200mm circular cylinder, 2- 315mm circular cylinder, 3- 400mm circular cylinder, 4square cylinder, 5- diamond cylinder)

The maximum slamming coefficients seem to hover at a range of 3.85 to 5.04 for circular cylinders (Fig. 3), agreeable with earlier literature review findings of a maximum slamming coefficient value of 5.15 [4]. However it seems that for a square cylinder, with its frontal flat plate perpendicular to the breaking wave propagation direction, will suffer a maximum slamming coefficient of as high as 6.7 in this present experimental work. However when the breaking wave attacks the square cylinder from a contact angle of 45 degrees, effectively rendering the test case into a diamond cylinder, the maximum slamming coefficient is about 3.76 , lowest of the 5 test cylinders. Cylinder 3, having a cylindrical diameter of $400 \mathrm{~mm}$, is the only test cylinder having a non-slenderness ratio of $\left(\frac{D}{\lambda}\right)>0.2$, rebounding waves from the cylindrical structure were observed towards onset of breaking. For the sake of consistency to focus on the slamming coefficient of slender structures, the $400 \mathrm{~mm}$ diameter cylinder would be taken off in the latter discussion for slamming coefficient discussion. 


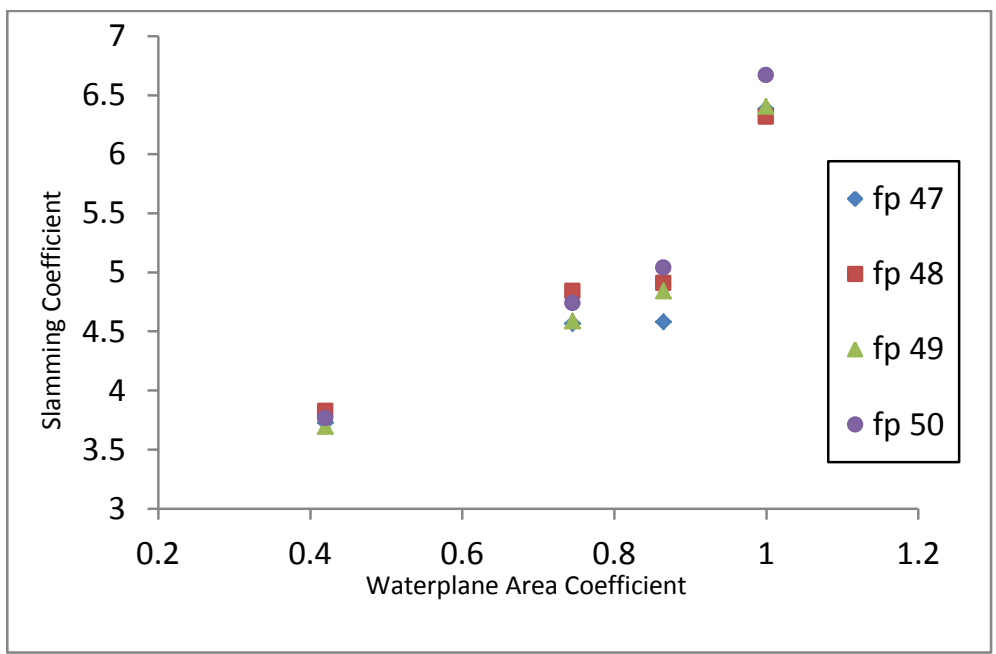

Fig. 4 Maximum slamming coefficient for cylindrical structures with different waterplane area coefficient during onset of breaking

The purpose of the above figure (Fig. 4) is to investigate on the impacts of the cross section geometry of the cylinder has on the resultant maximum slamming coefficient. As Chan and Melville [1] pointed out that the air entrapment between the structure and the plunging jet would have direct implications on the resultant maximum slamming force. Above figure (Fig. 4) concluded a positive correlation between the Waterplane Area Coefficient and the maximum slamming coefficient could be observed. This would mean that different geometry fullness of the cylinder would have different associated air entrapment capabilities and, hence different slamming load contribution during onset of plunging breakers.

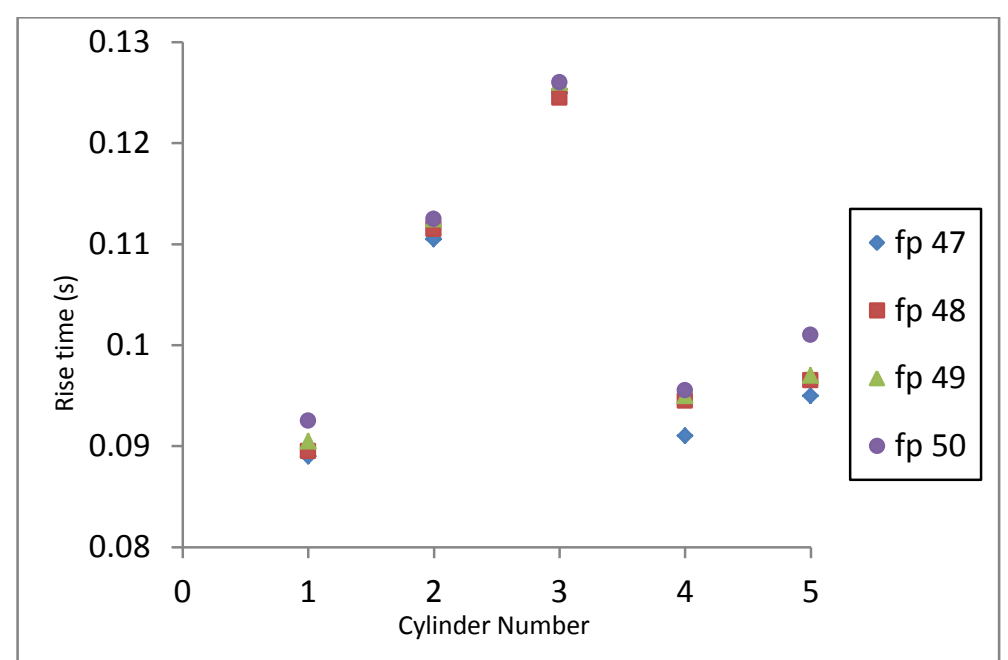

Fig. 5 Rise time for different wave intensities. (1- 200mm circular cylinder, 2- 315mm circular cylinder, 3-400mm circular cylinder, 4- square cylinder, 5- diamond cylinder) 
Chan and Melville [1] \& Blackmore and Hewson [12] concluded that the rise time does have a negative correlation with the slamming pressure. Chan and Melville [1] try to create different rise time by shifting the spatial location of the cylinder, in order to track the associated slamming pressure amongst different maturity of the plunging breaker. In this experimental work, the rise time were adjusted based on different intensities of plunging breaker (Fig. 5, Eq. 7 \& Eq. 9). It's shown on above figure that a lower rise time could be observed for higher breaking intensity breakers. The rise time at $f_{\mathrm{p}}=0.47 \mathrm{~Hz}$, could be observed to be up to $5 \%$ lower than at $f_{\mathrm{p}}=0.5 \mathrm{~Hz}$.

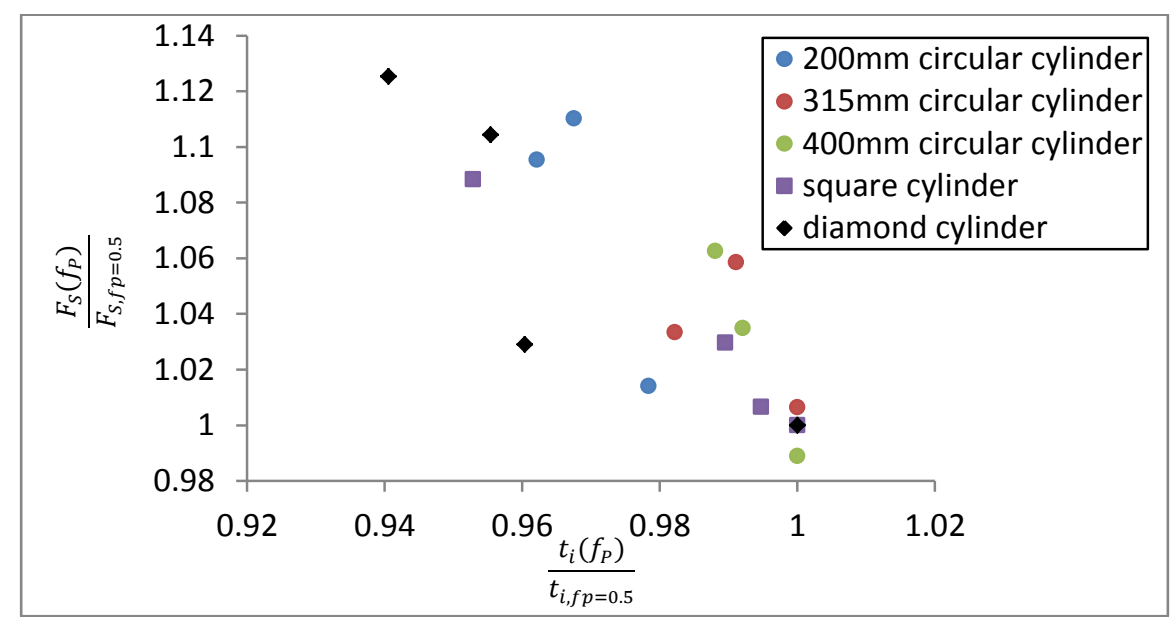

Fig. 6 Maximum Slamming Force ratio vs Rise Time ratio comparison

Taking rise time and maximum slamming force at the weaker plunging breaker $\left(f_{\mathrm{p}}=\right.$ $0.5 \mathrm{~Hz}$ ) as a datum. The maximum slamming force ratio is plotted against the change in rise time ratio (Fig. 6). The above findings give similar conclusion with Chan and Melville [1] \& Blackmore and Hewson [12] that a lower rise time would lead to a higher maximum slamming force contribution. 


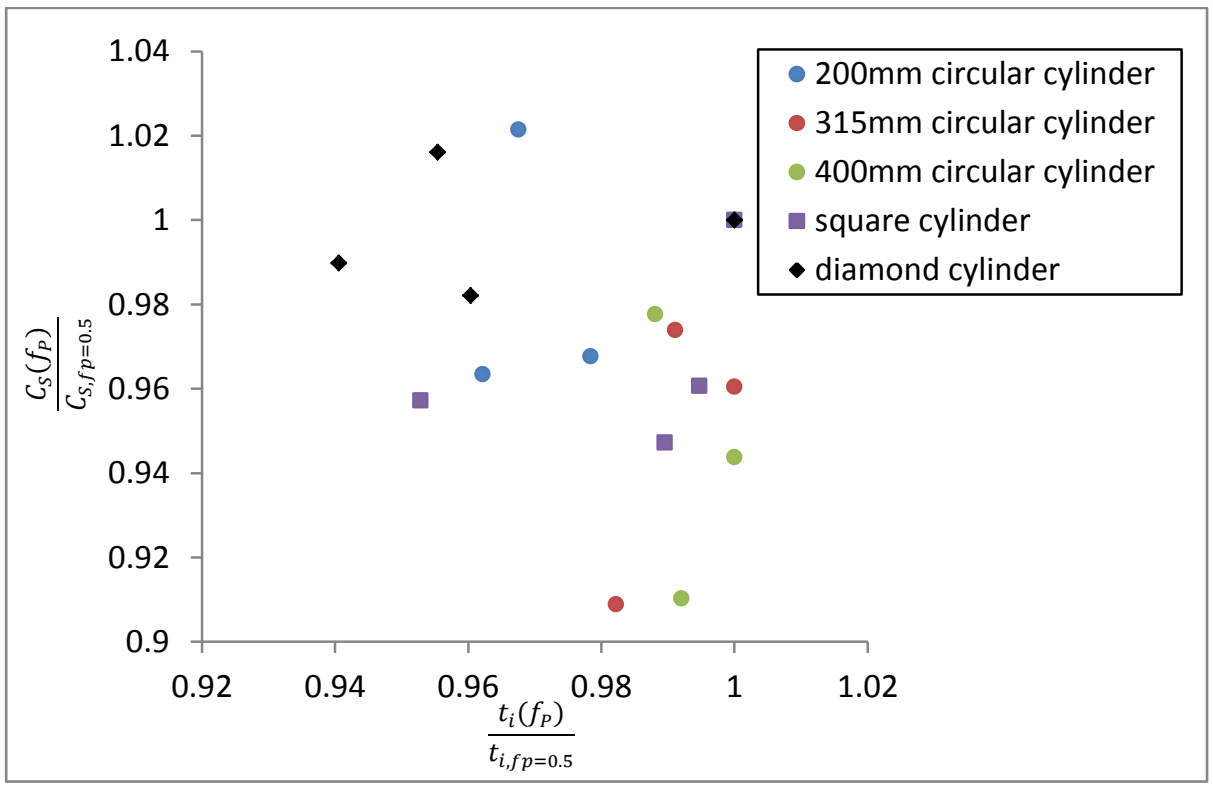

Fig. 7 Maximum Slamming Coefficient ratio vs Rise Time ratio comparison

Applying Eq. 5, the maximum slamming coefficient is obtained from the derived maximum slamming load. Although there is higher maximum slamming load relation (Fig. 6), however, due to the higher associated kinematics of the stronger plunging breaker, the increased in the maximum slamming load is offset by the increased wave kinematics. This results in having no distinct correlation between the maximum slamming coefficient and rise time (Fig. 7), for same plunging breaking maturity. This result seems to suggest that the lower rise time that is resulted due to different breaking wave intensity $\left(f_{\mathrm{P}}\right)$ does not affects the slamming coefficient. 


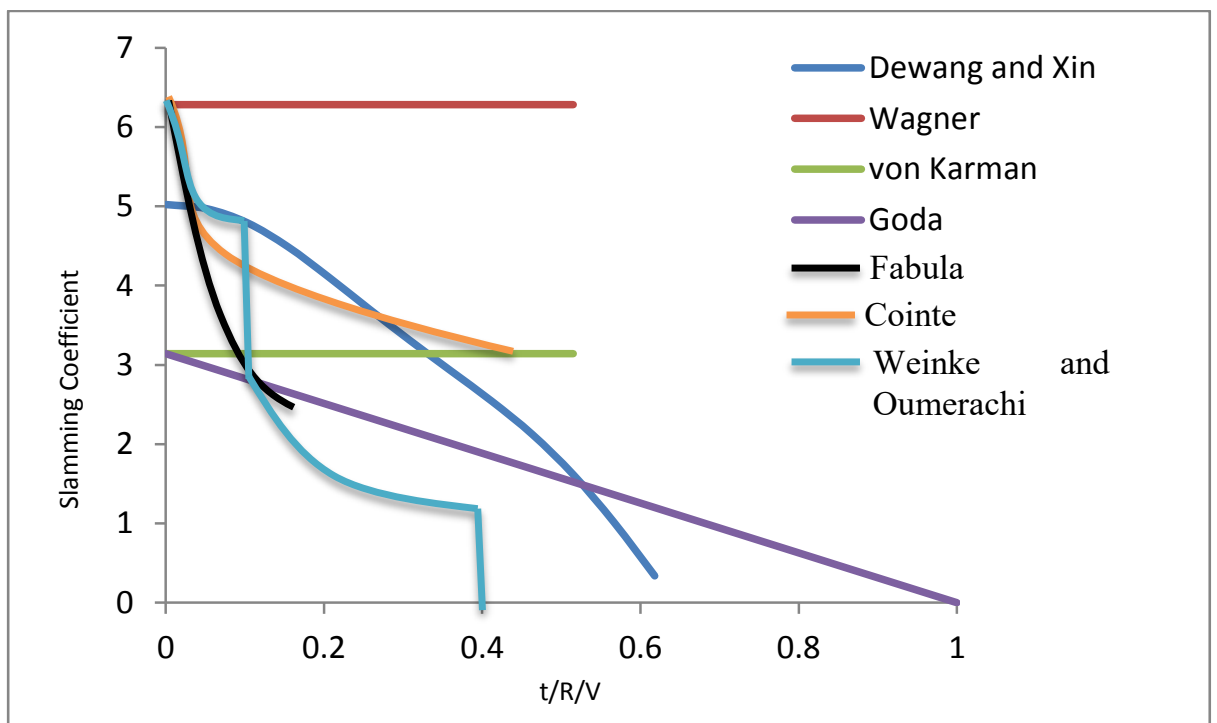

Fig. 8 Comparison of time histories of the slamming coefficient $(t=$ time, $R=$ cylinder radius, $\mathrm{V}=$ velocity) $[13,14,15,16,17]$

Earlier days researchers $[13,14]$ focused only the initial maximum slamming coefficient without focusing on the slamming coefficient time histories. Later on, researchers $[2,15,16,17]$ tried to present the slamming load coefficient as a function of time. Past researchers has attempted to describe the maximum slamming load coefficient upon initial impact, with values ranging from $\pi, 5.15$ [3], and $2 \pi$. Above (Fig. 4) showed a maximum slamming load coefficient ranging from 4.54 to 5.05 for circular cylinders, agreeing more with the DNV classification guidelines [3].

Above Fig. 8 findings, this experimental results and Goda [2] noted a linear slamming load coefficient decaying phenomenon. However, the above experiment finding has the closest fit to Cointe's [15].

\section{Conclusions}

There are classification rules on the slamming load coefficient to use whilst designing offshore structures to withstand plunging breakers [3]. However current classification rule on the maximum slamming coefficient is limited to a 'one size fits all' scenario. This might leads one to wonder if the resultant design breaking wave force could be too conservative in certain conditions.

Whilst there is no distinct relation with the slamming coefficient and the rise time for a pre-matured plunging breaker (that deals the most destructive slamming force [1]), however in this experimental work, its shown that the geometrical cross section of the cylinders do play a significant part in the maximum slamming coefficient. Future work could include exploring using cylinders of different surface roughness or 
even other complex geometrical cross section areas to relate to the maximum slamming coefficient.

One of the major challenges faced for deriving the results of the slamming load coefficient from the slamming load force, is the determination of the breaking wave celerity. Breaking wave celerity has been a complicated problem to solve (Chapter 1.2). Literature review discussed in Chapter 1.2 concluded that different methodologies would yield different breaking wave kinematic readings. Classification rules [3] give a $20 \%$ tolerance while estimating the breaking wave kinematics to be use while computing the design breaking wave load, due to the unpredictable kinematics of breaking wave. The use of linear theory for estimating phenomenon with higher nonlinearity has proven to be inaccurate by several researchers $[8,9,10,11]$.

Estimation of the resultant design breaking wave slamming load is not only limiting to breaking wave kinematics, but also largely affected by the slamming load coefficient. This experimental work involves analyzing the breaking wave slamming load amongst cylinder with different geometries across different breaking intensities. This experiment concluded that the slamming load coefficient is largely affected by the geometrical cross section of cylinder. Current classification design rules recommend a fixed maximum slamming load coefficient, regardless of the geometrical shape of the cylinder could resulted in an overly conservative design breaking wave loading.

\section{ACKNOWLEDGEMENTS}

The authors would like to thank Singapore Economic Development Board and Lloyd's Register Singapore Pte Ltd for funding this experimental work. Special thanks to the Newcastle University Hydrodynamics Lab team for their kind support to make this experimental work possible

\section{References}

1. Chan E.S, W.K. Melville., Deep-water plunging wave pressures on a vertical plane wall. Proc. R. Soc. Lond. A 417, 95-131 (1988)

2. Goda, Y.Haranaka S., Kitahata. M., Study of impulsive Breaking Waves Forces on Piles. Report of Port and Harbor Research Institute, 5(6): 1-30

3. Veritas,D.N., RP-C205 Environmental Conditions and Environmental Loads, https://rules.dnvgl.com/docs/pdf/dnv/codes/docs/2010-10/rp-c205.pdf , last accessed 2018/2/2.

4. Campbell, T. and Weynberg, P. Measurement of parameters affecting slamming - final report. Wolfson Marine Craft Unit Report No. 440 - University of Southampton.

5. Shore Protection Manual Vol 2. Coastal Engineering, Research Center, Department of the Army.

6. De Wang C, Xin Wang, Arun Kr Dev, L.B. Tao, Y.L. Zhang., Slamming Force contribution due to plunging breakers on circular, square and diamond cylinders. Proceedings of the ASME 2019, $38^{\text {th }}$ International Conference on Ocean, Offshore and Arctic Engineering (2019)

7. Rapp, Melville, Laboratory measurements of deep water breaking waves. Phil. Trans. R. Soc. Lond. A 331, 735-800. (1990) 
8. Perlin. M., He. J.H., Bernal. L.O., An experimental study of deep water plunging breakers. Physics of Fluids, Vol:8, Issue:9, 2365-2375 (1996)

9. Baldock T.E, Swan C., Taylor P.H., A laboratory study of nonlinear surface waves on water' Phil. Trans. R. Soc. Lond. A 354, 649-676 (1996).

10. Cui Cheng, Z.N.-C.-H. A study on kinematics characteristic of Freak Wave. China Ocean Eng, 391-402

11. De Wang C, T.L. Experimental research on kinematics of breaking waves. Journal of Hydrodynamics, 390-394 (2018).

12. P.A. Blackmore., P.L. Hewson., Experiments on Full-Scale wave impact pressures. Coastal Engineering, 8, 331-346 (1984).

13. von Karman, T., The impact on seaplane floats during landing. National Advisory Committee for Aeronautics. Technical Note, vol. 321 (1929)

14. Wagner, H., U " ber Stog-und Gleitvorg7nge an der Oberfl7che von Flqssigkeiten. Zeitschrift fqr angewandte Mathematik und Mechanik 12 (4), 193-215 (1932) (in German)

15. Cointe, R., Armand, J.-L., Hydrodynamic impact analysis of a cylinder. Journal of Offshore Mechanics and Arctic Engineering 109, 237-243 (1989)

16. Fabula, A.G., Ellipse-fitting approximation of two-dimensional, normal symmetric impact of rigid bodies on water. Proceedings of the $5^{\text {th }}$ Midwestern Conference on Fluid Mechanics, 299-315 (1957)

17. Wienke, J., Druckschlagbelastung auf schlanke zylindrische Bauwerke durch brechende Wellen-theoretische und grogmagst7bliche Laboruntersuchungen -PhD-thesis, TU Braunschweig, (in German) (2001) 